\title{
Analisis kompetensi calon guru matematika praktikan program pengenalan lapangan (PPL) FKIP Unswagati di salah satu SMA Kota Cirebon
}

\author{
Dede Trie Kurniawan ${ }^{,}$, Setiyani ${ }^{\text {, dan Sri Maryanti }}{ }^{2}$ \\ 1. FKIP Unswagati Cirebon, Jl. Terusan Pemuda No. o1A Kota Cirebon, Jawa \\ Barat, Indonesia
}

2. Pendidikan Biologi FTK UIN Sunan Gunung Djati Bandung, Jl. A.H. Nasution

No. 105, Bandung 40614, Indonesia

dhe3kurniawan@gmail.com

DOI : $10.15575 /$ ja.v5i1.4227

Received: 02 Januari 2019; Accepted: 12 April 2019; Published: 29 Juni 2019

\begin{abstract}
ABSTRAK
Penelitian ini bertujuan menganalisis ketercapaian komptensi pedagogik, profesional, sosial, dan kepribadian mahasiswa calon guru matematika praktikan Program Pengenalan Lapangan (PPL) di salah satu SMA Kota Cirebon. sebagai Lembaga Pendidikan Tenaga Kependidikan (LPTK). Fakultas Keguruan dan Ilmu Pendidikan (FKIP) Unswagati Cirebon memiliki tugas dan tanggung jawab menghasilkan calon-calon guru yang profesional di wilayah III Cirebon. Program PPL yang diselenggarakan oleh FKIP Unswagati bertujuan memberikan pengalaman lapangan kepada mahasiswa tentang profesionalisme dalam bidang keguruan yang telah dipelajari oleh mahasiswa. Metode penelitian menggunakan metode deskriptif. Populasi penelitian adalah seluruh mahasiswa praktikan PPL kependidikan FKIP Unswagati di salah satu SMA Kota Cirebon dalam rentang waktu tahun 2015 - 2017. Berdasarkan hasil yang diperoleh dapat diketahui bahwa secara garis besar praktikan tingkat III lebih baik daripada praktikan tingkat IV dalam perolehan tingkat komptensi calon guru, baik itu kompetensi profesional, kompetensi personal, kompetensi sosial, dan kompetensi pedagogik.
\end{abstract}

Kata kunci: Kompetensi Calon Guru, Mahasiswa PPL Kependidikan

\begin{abstract}
This study aims to analyze the achievement of pedagogic, professional, social, and personality competencies of prospective mathematics teacher students practicing the Field Recognition Program (PPL) in one of the Cirebon High Schools. as an Educational Personnel Education Institution (LPTK). The Unswagati Teaching and Education Faculty (FKIP) in Cirebon has the task and responsibility of producing professional teacher candidates in Cirebon Region III. The PPL program organized by Unswagati FKIP aims to provide field experience to students about the professionalism in the field of teacher training that has been studied by students. The research method uses descriptive methods. The study population was all students practicing PPL Unswagati FKIP in one of the Cirebon high schools in the period of 2015 - 2017. Based on the results obtained, it can be seen that in general, the level III practitioner is better than the level IV practitioner in obtaining the competency level of prospective teachers, both professional competence, personal competence, social competence, and pedagogical competence.
\end{abstract}

Keywords: Competency of Teacher Candidates, PPL Education Students 


\section{PENDAHULUAN}

Program pengenalan lapangan adalah sebuah sarana untuk menghasilkan guru professional. Adapun ciri dari guru profesional memiliki karakteristik: (1) memiliki kemampuan menciptakan iklim belajar yang kondusif, (2) kemampuan mengembangkan strategi dan manajemen pembelajaran, (3) memiliki kemampuan memberikan umpan balik dan penguatan, (4) memiliki kemampuan untuk peningkatan diri (Mulyasa, 2013). Karakteristik tersebut dapat diringkas menjadi tiga domain besar, yaitu knowledge (pedagodik dan profesional), skill/practice (keterampilan mengajar), dan attribute (pengembangan diri). Lima bidang keterampilan profesional yang dibutuhkan untuk kemajuan profesi guru meliputi: keterampilan pengetahuan, keterampilan berpikir, keterampilan personal, atribut personal, dan keterampilan praktik (Nicholis, 2001).

Program Praktik Pengenalan Lapangan Kependidikan (PPL) di FKIP Unswagati Cirebon dilaksanakan oleh setiap program studi di lingkungan Fakultas Keguruan dan Ilmu Pendidikan (FKIP). Program ini dibawah naungan langsung FKIP yang diselenggarakan oleh Unit Pelaksana Teknis (UPT) PPL. Pelaksanaan PPL dilaksanakan satu kali dalam setahun yakni pada semester 6 menuju 7 untuk empat program studi (program studi pendidkan sastra dan bahasa indonesia, pendidikan bahasa inggris, pendidikan matematika, dan pendidikan ilmu ekonomi).

PPL adalah kegiatan akademik yang dilakukan mahasiswa FKIP dalam rangka menerapkan dan mengembangkan kompetensi profesional, pedagogik, kepribadian, dan sosial yang berwujud dalam kegiatan praktik keguruan, penelitian, dan pengelolaan pendidikan. Kinerja mahasiswa praktikan dalam aspek pengetahuan, keterampilan, sikap dan perilaku keguruan yang dialami secara nyata di madrasah atau sekolah.

PPL merupakan kegiatan intrakurikuler yang mencakup kegiatan praktik mengajar, penelitian kependidikan, dan pengelolaan kependidikan di madrasah atau sekolah.
Dengan demikian, PPL mencakup Tri Dharma Perguruan Tinggi. Sebagai mata kuliah, PPL berbobot 4 sks yang dilaksanakan sepenuhnya di madrasah/sekolah praktik.

Tujuan umum kegiatan PPL sebagaimana tercantum dalam buku pedoman PPL FKIP Unswagati Cirebon adalah agar para praktikan memperoleh pengalaman pendidikan di lapangan, sebagai upaya lembaga untuk membentuk tenaga-tenaga profesional. Pengalaman yang diharapkan meliputi pengalaman pengetahuan, keterampilan, sikap, profesionalisme, dan pengalaman menerapkan serta menyelenggarakan pendidikan dan pengajaran dengan penuh dedikasi dan tanggung jawab, baik di sekolah maupun di luar sekolah.

Tujuan khusus kegiatan PPL adalah agar mahasiswa:

1. Praktikan dapat menambah wawasan pengetahuan, baik teori maupun praktik pada bidang disiplin ilmu kependidikan.

2. Praktikan dapat menambah pengetahuan baik teori maupun praktik sesuai dengan program studinya.

3. Praktikan dapat melakukan proses belajar-mengajar yang baik sesuai dengan tuntutan profesi seorang guru.

4. Praktikan mampu mengembangkan etika-etika keguruan sesuai dengan tuntutan seorang guru atau tenaga kependidikan yang profesional.

Pentingnya program penelitian ini dikarenakan secara teknis selama ini, evaluasi hanya dilakukan melalui rekapan nilai dengan bobot tertentu yang ditinjau dari nilai keseharian, nilai ujian, dan nilai laporan. Evaluasi yang dilakukan tidak tersistematis, kalaupun ada laporan masih bersifat sangat umum yang didasarkan pada kesan umum yang mereka tangkap. Memang ada data laporan tetapi bukan data terperinci yang lebih diutamakan, tetapi lebih pada bahwa program telah dilaksanakan.

Faktor utama yang menentukan kualitas perkuliahan adalah dosen. Oleh karena itu, program harus dapat memberikan manfaat kepada dosen dalam rangka meningkatkan kualitas pembimbingan praktikan yang 
diembannya. Selain itu, karena tujuan akhir setiap program peningkatan kualitas perkuliahan adalah dapat memberikan layanan terbaik kepada mahasiswa, maka program harus memberi dampak pada peningkatan kepuasan mahasiswa serta hasil studi mahasiswa dan para siswa yang diajarkan. Dengan demikian, assesmen terhadap dampak program juga sangat penting dilakukan, keberhasilan evaluasi ini akan menjadi dampak yang positif pada FKIP Unswagati.

Adapun rumusan masalah dari penelitian Analisis Kompetensi Calon Guru Matematika Praktikan Program Pengenalan Lapangan (PPL) FKIP Unswagati di Salah Satu SMA Kota Cirebon adalah untuk menganalisis tingkat ketercapaian kompetensi pedagogik, profesional, sosial, dan kepribadian yang dikaitkan dengan efektifitas pelaksanaan PPL. Secara rinci tujuan khusus tersebut adalah untuk:

1. Menganalisis tingkat kompetensi pedagodik, kompetensi profesional, kompetensi sosial, dan kompetensi kepribadian mahasiswa calon guru.

2. Mendeskripsikan Kualifikasi dan beban kerja mahasiswa calon guru dalam menjalankan PPL.

3. Menganalisis faktor-faktor yang menjadi kendala pencapaian tujuan program Pengenalan Lapangan Kependidikan (PPL).

4. Mendeskripsikan proses pelaksanaan PPL dalam membina kompetensi pedagodik, kompetensi profesional, kompetensi sosial, dan kompetensi kepribadian mahasiswa calon guru.

Tujuan umum evaluasi program PPL adalah diketahuinya efektivitas program PPL pada pertengahan masa implementasi program ditinjau dari dampaknya pada peningkatan kualitas mahasiswa peserta PPL. Secara khusus evaluasi bertujuan untuk memperoleh gambaran tentang:

1. Kinerja dosen pembimbing dalam meningkatkan kemampuan mahasiswa dalam kompetensi profesional, pedagogik, kepribadian, dan sosial.
2. Kinerja mahasiswa peserta PPL dalam kompetensi profesional, pedagogik, kepribadian dan sosial.

Informasi yang diperoleh dari evaluasi pelaksanaan program PPL ini akan menjadi masukan utama bagi pihak-pihak yang berkepentingan, sebagai landasan empirik untuk merancang perbaikan terhadap pelaksanaan program PPL, sehingga pada akhir implementasinya PPL berhasil mencapai tujuan-tujuannya.

\section{METODE}

Penelitian ini menggunakan metode deskriptif dan bersifat ex post facto yang berkenaan dengan kondisi yang sedang terjadi apa adanya dan bukan akibat dari suatu manipulasi eksperimental. Populasi penelitian adalah seluruh mahasiswa calon guru FKIP Unswagati yang mejalani PPL di salah satu SMA Kota Cirebon. Informasi data diperoleh melalui observasi, angket, wawancara, dan produk. Tahap pengumpulan data dilakukan melalui observasi: 1) mengamati kemampuan mahasiswa calon guru dalam merencanakan pembelajaran, 2) mengamati kemampuan mahasiswa guru dalam mengimplementasikan pembelajaran, dan 3) mengamati kemampuan mahasiswa calon guru dalam mengevaluasi hasil dan proses pembelajaran. Aspek-aspek yang diamati terkait dengan kompetensi pedagogik, kompetensi sosial, kompetensi profesional dam kompetensi kepribadian mahasiswa calon guru selama menjalani PPL di sekolah mitra. Analisis data dilakukan secara kualitatif disertai interpretasinya, kemudian dibuat kesimpulan.

Sesuai dengan tujuan evaluasi, aspekaspek yang menjadi fokus evaluasi mencakup kinerja dosen pembimbing, peningkatan pengetahuan dan keterampilan peserta dan kinerja mengajar mahasiswa. Hubungan antara level evaluasi, fokus evaluasi, dan indikator evaluasi yang diterapkan pada evaluasi PPL diperlihatkan pada Tabel 1.

Tabel 1. Parameter atau Variabel Evaluasi 
Dede Trie Kurniawan, Setiyani,

Sri Maryanti

\begin{tabular}{|c|c|c|}
\hline Level Evaluasi & $\begin{array}{l}\text { Fokus } \\
\text { Evaluasi }\end{array}$ & $\begin{array}{l}\text { Indikator } \\
\text { Evaluasi }\end{array}$ \\
\hline \multirow[t]{2}{*}{$\begin{array}{l}\text { Reaksi } \\
\text { partisipan }\end{array}$} & $\begin{array}{l}\text { Kinerja dosen } \\
\text { pembimbing }\end{array}$ & $\begin{array}{ll}\text { - } & \text { Melakukan } \\
\text { kunjungan } \\
\text { observasi } \\
\text { kelas } \\
\text { - } \\
\text { Melakukan } \\
\text { pembimbinga } \\
\text { n PPL } \\
\text { Melakukan } \\
\text { pembimbinga } \\
\text { n penelitian } \\
\text { pendidikan } \\
\end{array}$ \\
\hline & $\begin{array}{l}\text { Kinerja guru } \\
\text { pamong }\end{array}$ & $\begin{array}{ll}\text { - } & \text { Melakukan } \\
\text { pembimbinga } \\
\text { n RPP } \\
\text { - Melakukan } \\
\text { pembimbinga } \\
\text { n di kelas } \\
\text { - Memberikan } \\
\text { penilaian, } \\
\text { saran dan } \\
\text { kritik }\end{array}$ \\
\hline $\begin{array}{l}\text { Hasil belajar } \\
\text { partisipan }\end{array}$ & $\begin{array}{l}\text { Peningkatan } \\
\text { pengetahuan } \\
\text { konten } \\
\text { akademik, } \\
\text { pedagogi dan } \\
\text { profesional } \\
\text { peserta PPL }\end{array}$ & $\begin{array}{l}\text { - } \begin{array}{l}\text { Peningkatan } \\
\text { pengetahuan } \\
\text { konten }\end{array} \\
\text { Peningkatan } \\
\text { pengetahuan } \\
\text { pedagogi dan } \\
\text { profesional }\end{array}$ \\
\hline $\begin{array}{l}\text { Dukungan } \\
\text { organisasi dan } \\
\text { belajar }\end{array}$ & $\begin{array}{l}\text { Dukungan } \\
\text { organisasi } \\
\text { sekolah }\end{array}$ & $\begin{array}{l}\text { Keterlibatan } \\
\text { kepala sekolah } \\
\text { dalam PPL }\end{array}$ \\
\hline $\begin{array}{l}\text { Penggunaan } \\
\text { pengetahuan } \\
\text { dan } \\
\text { keterampilan } \\
\text { baru }\end{array}$ & $\begin{array}{l}\text { Kinerja } \\
\text { mengajar } \\
\text { peserta PPL di } \\
\text { kelas }\end{array}$ & $\begin{array}{l}\text { - Penguasaan } \\
\text { materi } \\
\text { - Ketepatan } \\
\text { metode } \\
\text { pembelajaran } \\
\text { - Pemanfaatan } \\
\text { sumber } \\
\text { belajar/media } \\
\text { - Keaktifan siswa } \\
\text { - Penilaian } \\
\text { proses dan hasil } \\
\text { belajar } \\
\text { - Penggunaan } \\
\text { bahasa } \\
\end{array}$ \\
\hline $\begin{array}{l}\text { Hasil belajar } \\
\text { siswa }\end{array}$ & $\begin{array}{l}\text { Hasil belajar } \\
\text { siswa yang } \\
\text { diajar oleh } \\
\text { mahasiswa } \\
\text { PPL }\end{array}$ & $\begin{array}{l}\text { Hasil belajar } \\
\text { siswa mencapai } \\
\text { KKM }\end{array}$ \\
\hline
\end{tabular}

Prosedur umum untuk pelaksanaan evaluasi ini mengkuti langkah-langkah yang secara skematik disajikan pada gambar berikut.

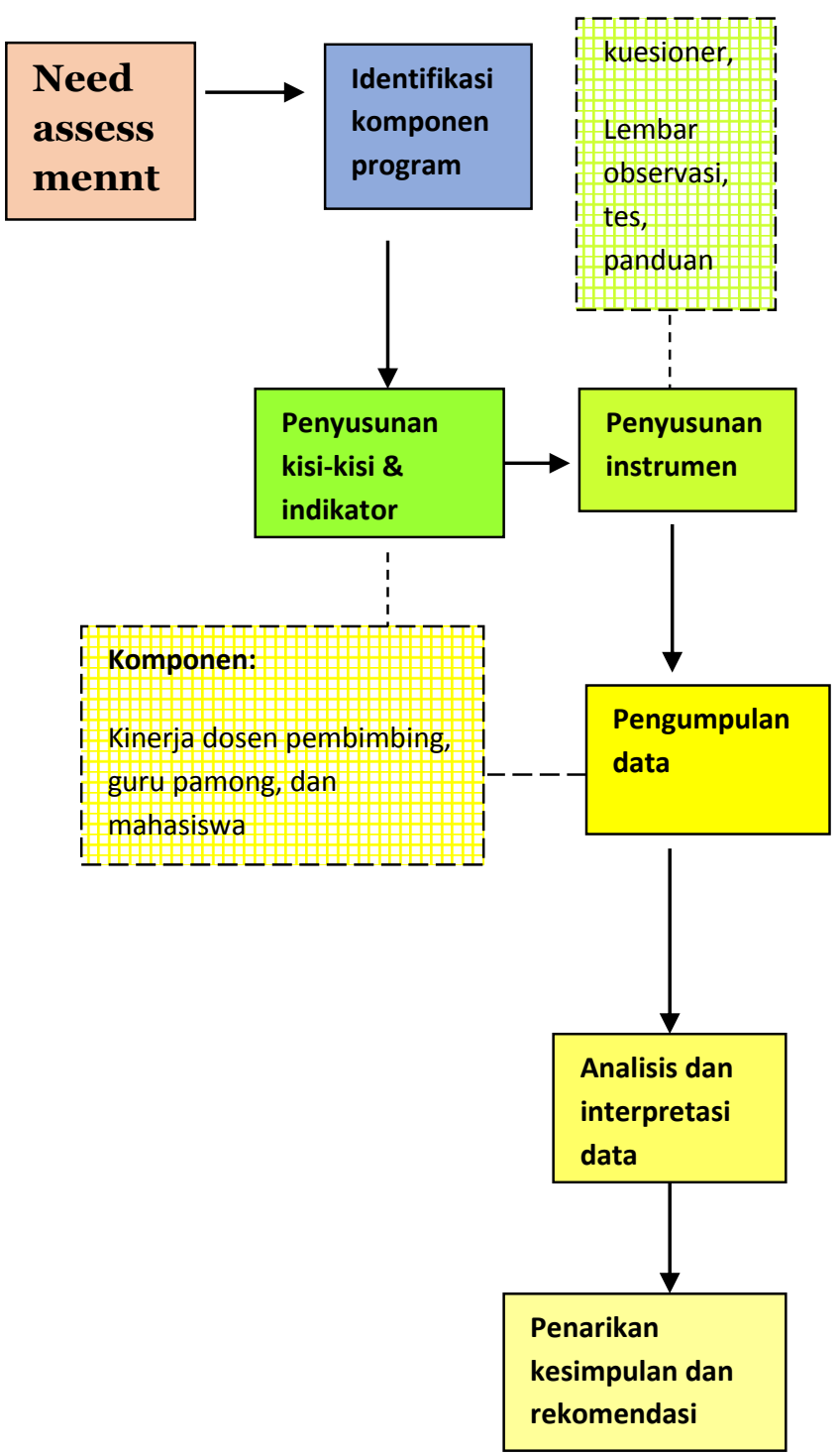

Gambar 1. Diagram Alur Proses Evaluasi

Adapun definisi operasional untuk kompetensi calon guru matematika yang akan di nilai dapat dijelaskan seperti pada Tabel 2 berikut ini.

Tabel 2. Penilaian Kompetensi Calon Guru

\begin{tabular}{|ll|l|}
\hline Kompetensi & Cara Menilai \\
\hline Pedagogik & Menguasai & Pengamatan \\
\hline karakteristik & dan \\
peserta didik & pemantauan \\
\hline
\end{tabular}




\begin{tabular}{|c|c|}
\hline Kompetensi & Cara Menilai \\
\hline $\begin{array}{l}\text { Menguasasi teori } \\
\text { belajar dan prinsip- } \\
\text { prinsip } \\
\text { pembelajaran yang } \\
\text { mendidik }\end{array}$ & Pengamatan \\
\hline $\begin{array}{ll}\text { 3. } & \text { Pengembangan } \\
\text { kurikulum }\end{array}$ & Pengamatan \\
\hline $\begin{array}{ll}\text { 4. } & \text { Kegiatan } \\
\text { pembelajaran yang } \\
\text { mendidik }\end{array}$ & Pengamatan \\
\hline $\begin{array}{ll}\text { 5. } & \text { Pengembangan } \\
\text { potensi peserta } \\
\text { didik }\end{array}$ & $\begin{array}{l}\text { Pengamatan } \\
\text { dan } \\
\text { pemantauan }\end{array}$ \\
\hline $\begin{array}{l}\text { 6. Komunikasi dengan } \\
\text { peserta didik }\end{array}$ & Pengamatan \\
\hline $\begin{array}{ll}\text { 7. Penilaian dan } \\
\text { evaluasi }\end{array}$ & Pengamatan \\
\hline \multicolumn{2}{|l|}{ Kepribadian } \\
\hline $\begin{array}{l}\text { Bertindak sesuai } \\
\text { dengan norma } \\
\text { agama, hukum, } \\
\text { sosial, dan } \\
\text { kebudayaan } \\
\text { nasional } \\
\end{array}$ & $\begin{array}{l}\text { Pengamatan } \\
\text { dan } \\
\text { pemantauan }\end{array}$ \\
\hline $\begin{array}{ll}\text { 2. } & \text { Menunjukkan } \\
\text { pribadi yang dewasa } \\
\text { dan teladan }\end{array}$ & $\begin{array}{l}\text { Pengamatan } \\
\text { dan } \\
\text { pemantauan }\end{array}$ \\
\hline $\begin{array}{l}\text { 3. } \\
\text { Etos kerja, } \\
\text { tanggung jawab } \\
\text { yang tinggi, rasa } \\
\text { bangga menjadi } \\
\text { guru }\end{array}$ & $\begin{array}{l}\text { Pengamatan } \\
\text { dan } \\
\text { pemantauan }\end{array}$ \\
\hline \multicolumn{2}{|l|}{ Sosial } \\
\hline $\begin{array}{l}\text { 1. Bersikap inklusif, } \\
\text { bertindak obyektif, } \\
\text { serta tidak } \\
\text { diskriminatif }\end{array}$ & $\begin{array}{l}\text { Pengamatan } \\
\text { dan } \\
\text { pemantauan }\end{array}$ \\
\hline $\begin{array}{ll}\text { 2. } & \text { Komunikasi dengan } \\
\text { sesama guru, tenaga } \\
\text { kependidikan, } \\
\text { orang tua, peserta } \\
\text { didik, dan } \\
\text { masyarakat }\end{array}$ & Pemantauan \\
\hline \multicolumn{2}{|l|}{ Profesional } \\
\hline $\begin{array}{l}\text { 1. Penguasaan materi, } \\
\text { struktur, konsep, } \\
\text { dan pola pikir } \\
\text { keilmuan yang } \\
\text { mendukung mata } \\
\text { pelajaran yang } \\
\text { diampu } \\
\end{array}$ & Pengamatan \\
\hline $\begin{array}{ll}\text { 2. } & \text { Mengembangkan } \\
\text { keprofesionalan } \\
\text { melalui tindakan } \\
\text { yang reflektif } \\
\end{array}$ & Pemantauan \\
\hline
\end{tabular}

Instrumen yang akan digunakan untuk mengumpulkan data untuk keperluan evaluasi program PPL, yaitu:

1. Kuesioner pelaksanaan program PPL, dirancang untuk mengungkap reaksi peserta terhadap kinerja dosen pembimbing dan kinerja guru pamong

2. Tes kemampuan profesional guru, tes dirancang untuk mengungkap tingkat pengetahuan konten akademik, pedagogi, dan profesional.

3. Instrumen evaluasi kinerja mengajar mahasiswa PPL, diisi oleh dosen pembimbing, guru pamong, dan kepala sekolah.

4. Pedoman wawancara untuk kegiatan FGD.

5. Dokumentasi data nilai siswa yang diajar oleh mahasiswa PPL. 
Dede Trie Kurniawan, Setiyani, Sri Maryanti

Tabel 3. Level Evaluasi, Jenis Data, Sumber Data, dan Intrumen Pengumpul Data

\begin{tabular}{|l|l|l|l|}
\hline \multicolumn{1}{|c|}{ Level Evaluasi } & \multicolumn{1}{|c|}{ Jenis data } & Sumber data & \multicolumn{1}{c|}{ Intrumen } \\
\hline \multirow{2}{*}{ Reaksi partisipan } & $\begin{array}{l}\text { Kinerja dosen } \\
\text { pembimbing }\end{array}$ & Praktikan & $\begin{array}{l}\bullet \text { Kuesione } \\
\bullet \text { Pedoman wawancara }\end{array}$ \\
\cline { 2 - 4 } & $\begin{array}{l}\text { Kinerja guru } \\
\text { pamong }\end{array}$ & Praktikan & $\begin{array}{l}\bullet \text { Kuesioner } \\
\bullet \text { Pedoman wawancara }\end{array}$ \\
\hline $\begin{array}{l}\text { Dukungan } \\
\text { organisasi dan belajar }\end{array}$ & $\begin{array}{l}\text { Dukungan } \\
\text { orang sekolah }\end{array}$ & Praktikan & Kuesioner \\
\hline $\begin{array}{l}\text { Penggunan pengetah } \\
\text { an dan keterampilan } \\
\text { baru }\end{array}$ & $\begin{array}{l}\text { Kinerja } \\
\text { mengajar } \\
\text { peserta PPL di } \\
\text { kelas }\end{array}$ & $\begin{array}{l}\text { Guru } \\
\text { pamong dan } \\
\text { dosen } \\
\text { pembimbing }\end{array}$ & Lembar observasi \\
\hline
\end{tabular}


Data kuesioner dan data kualitatif notulasi FGD diinterprestasikan untuk memperoleh kesimpulan tentang kinerja dosen pembimbing dan guru pamong serta dukungan organisasi.

Hasil tes berupa profil kemampuan konten akademik, pedagogi, dan profesional diperbandingkan menggunakan statistik paired sample t-test dengan program SPSS, untuk menarik kesimpulan tentang dampak PPL terhadap peningkatan penguasaan kemampuan konten akademik, pedagogi, dan profesional mahasiswa.

Data hasil observasi kinerja mengajar, lebih lanjut dianalisis secara kualitatif untuk mengungkap seberapa banyak pengetahuan profesional, pedagogi, kepribadian, dan sosial dapat diaplikasikan mahasiswa PPL dalam pembelajaran di kelas.

Keseluruhan temuan-temuan yang diperoleh dari analisis data lebih lanjut digunakan untuk menarik kesimpulan tentang program PPL secara komprehensif, sebagaimana yang menjadi tujuan pelaksanaan evaluasi program PPL.

\section{HASIL DAN PEMBAHASAN}

Data hasil penelitian terdiri atas (1) rekapitulasi nilai rata-rata harian dan ujian praktikan PPL 4 program studi tingkat III dan IV, (2) rekapitulasi evaluasi kinerja dosen pembimbing lapangan, (3)rekapitulasi komptensi profesional, pribadi, sosial, dan pedagogik praktikan PPL 4 program studi tingkat III dan IV, dan (4) dokumentasi kegiatan penelitian. Data penelitian kemudian dianalisis, direkap, dan disajikan untuk selanjutnya digunakan untuk menjawab pertanyaan penelitian.

\section{Rekapitulasi Nilai Rata-rata Ujian Harian dan Ujian Praktik}

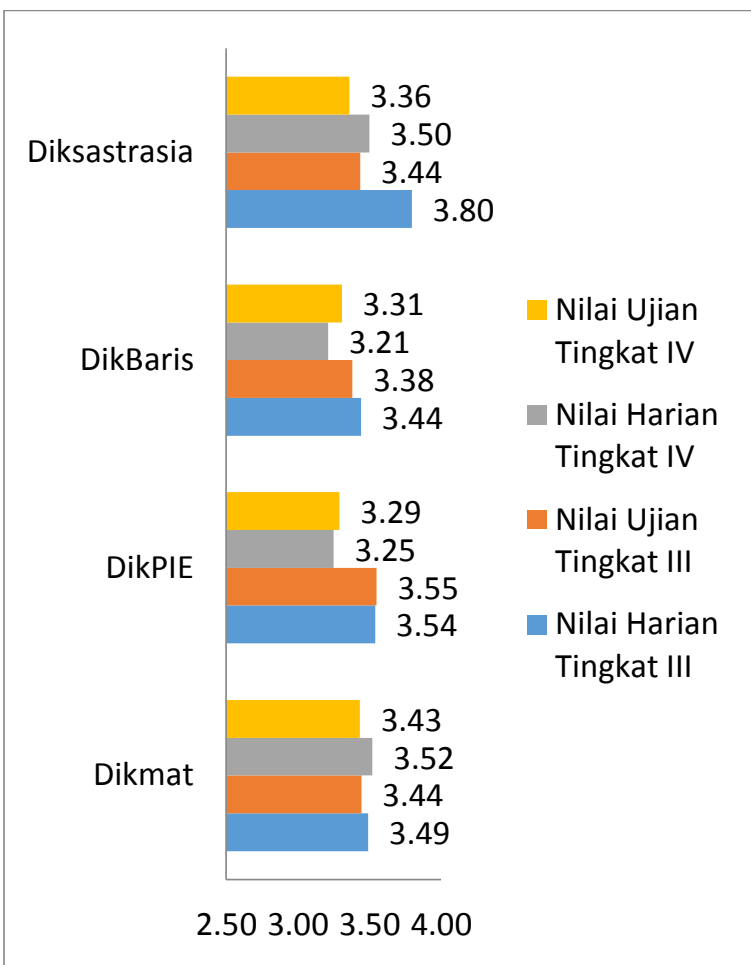

Gambar 2. Rekapitulasi Nilai Harian dan Nilai Ujian Mahasiswa Praktikan PPL di Salah Satu SMA Kota Cirebon (skala Maksimal adalah 4)

Salah satu tolak ukur keberhasilan mahasiswa dalam mengikuti kegiatan PPL adalah memperoleh nilai yang baik, pada nilai harian dan nilai ujian. Nilai harian didapatkan praktikan dari guru pamong dengan melihat kegiatan aktifitas yang dilakukan, sedangkan nilai ujian diperoleh ketika praktikan ujian mengajar dengan mengambil rata-rata nilai yang diberikan oleh kepala sekolah, guru pamong, dan dosen pembimbing lapangan.

Pada Prodi Pendidikan Matematika, nilai harian dan nilai ujian praktikan tingkat III dan IV tidak memiliki perbedaan yang cukup signifikan. Dilihat dari hasil penelitian ini praktikan tingkat III dan tingkat IV memiliki kesiapan yang sama, sehingga perbedaan tingkat pada pelaksanaan PPL tidak memberikan perbedaan yang cukup signifikan pada nilai harian dan nilai ujian praktikan. 


\section{Rekapitulasi Evaluasi Kinerja Dosen Pembimbing Lapangan}

Disamping data mengenai empat kompetensi praktikan PPL, penelitian ini juga meneliti efektifias dari kinerja dosen pembimbing lapangan selama kegiatan PPL berlangsung. Adapun yang menjadi indikator dari kinerja dosen pembimbing lapangan adalah membimbing secara individu dalam merencanakan kegiatan pengalaman lapangan dan memiliki disiplin yang tinggi, menyelenggarakan diskusi dengan mahasiswa mengenai pelaksanaan pengalaman lapangan, bersama guru pamong menilai mahasiswa mengenai penampilan mahasiswa dalam pelaksanaan latihan mengajar, memantapkan penampilan mahasiswa dalam kegiatan pengalaman lapangan, bersama guru pamong melaksanakan program bimbingan bagi praktikan, membimbing kemampuan keterampilan dasar mengajar, mengobservasi, mencatat dan menganalisis kegiatan dalam latihan pengalaman lapangan berdasarkan pola dan sistem pembelajaran yang ditetapkan, memperkaya dan memantapkan penampilan mahasiswa dalam kegiatan pengalaman lapangan dan menilai penampilan mahasiswa calon guru, kemudian memberikan laporan.

Tabel 4. Kinerja Dosen Pembimbing Lapangan di Salah Satu SMA Kota Cirebon

\begin{tabular}{|l|c|c|c|}
\hline $\begin{array}{l}\text { Tugas dosen } \\
\text { pembimbing }\end{array}$ & $\begin{array}{l}\text { Sangat } \\
\text { Baik }\end{array}$ & Baik & $\begin{array}{l}\text { Kurang } \\
\text { Baik }\end{array}$ \\
\hline $\begin{array}{l}\text { Dosen } \\
\text { pembimbing } \\
\text { melakukan } \\
\text { kunjungan ke } \\
\text { kelas saat } \\
\text { mahasiswa } \\
\text { melakukan } \\
\text { praktik mengajar }\end{array}$ & 30 & 50 & 20 \\
\hline $\begin{array}{l}\text { Dosen } \\
\text { pembimbing } \\
\text { memberikan } \\
\text { bimbingan } \\
\text { praktik mengajar } \\
\text { sesuai dengan } \\
\text { tugasnya. }\end{array}$ & 30 & 70 & 0 \\
\hline
\end{tabular}

\begin{tabular}{|l|c|c|c|}
\hline $\begin{array}{l}\text { Tugas dosen } \\
\text { pembimbing }\end{array}$ & $\begin{array}{l}\text { Sangat } \\
\text { Baik }\end{array}$ & Baik & $\begin{array}{l}\text { Kurang } \\
\text { Baik }\end{array}$ \\
\hline $\begin{array}{l}\text { Dosen } \\
\text { pembimbing } \\
\text { memberikan } \\
\text { pengarahan } \\
\text { dalam hal } \\
\text { penyusunan } \\
\text { perumusan } \\
\text { masalah } \\
\text { penelitian } \\
\text { kependidikan }\end{array}$ & 20 & 80 & 0 \\
\hline $\begin{array}{l}\text { Dosen } \\
\text { pembimbing } \\
\text { memberikan } \\
\text { pengarahan } \\
\text { dalam } \\
\text { penyusunan RPP } \\
\text { dan instrumen } \\
\text { untuk } \\
\text { pembelajaran }\end{array}$ & & & \\
\hline $\begin{array}{l}\text { Dosen } \\
\text { pembimbing } \\
\text { memberikan } \\
\text { bimbingan dalam } \\
\text { penyusunan } \\
\text { laporan akhir } \\
\text { dan jurnal PPL } \\
\text { kependidikan }\end{array}$ & 40 & 50 & 20 \\
\hline
\end{tabular}

\section{Rekapitulasi Kompetensi Praktikan PPL}

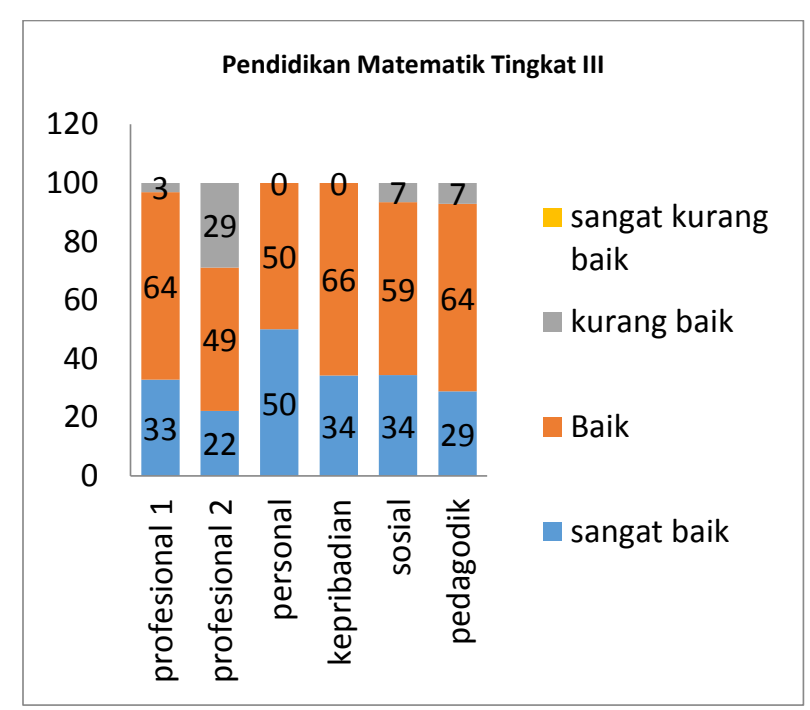


Dede Trie Kurniawan, Setiyani, Sri Maryanti

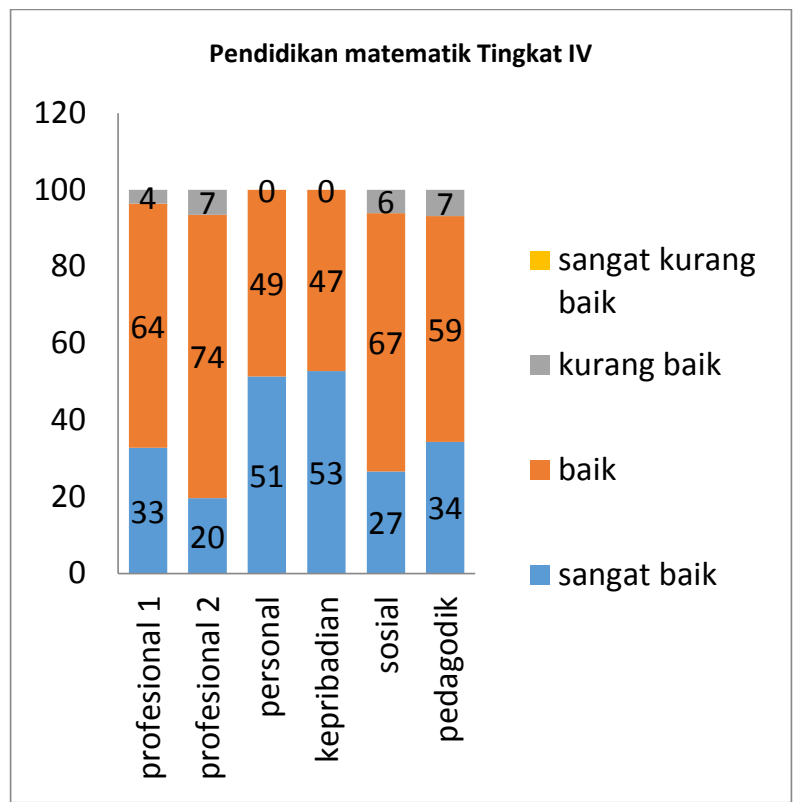

Gambar 3 Diagram Komptensi Praktikan PPL Pendidikan Matematika

Kompetensi dasar yang harus dimiliki oleh mahasiswa calon guru meliputi kompetensi profesional, kompetensi personal, kompetensi sosial, dan kompetensi pedagogik. Penelitian ini membahas empat kompetensi tersebut berdasarkan tingkat mahasiswa yaitu mahasiswa tingkat III dan IV pada Prodi Matematika. Kompetensi Profesional I calon guru Prodi Matematika Tingkat III, sebanyak $33 \%$ memiliki kriteria sangat baik, 64\% memliki kriteria baik, dan 3\% memiliki kriteria kurang baik. Sedangkan pada Prodi Pendidikan Matematika Tingkat IV sebanyak 33 \% memiliki kriteria sangat baik, 64\% memiliki kriteria baik, dan 4\% memliki kriteria kurang baik. Dilihat dari hasil pengamatan ini, terlihat bahwa penguasaan materi, struktur, konsep, dan pola pikir keilmuan yang mendukung mata pelajaran yang diampu oleh praktikan yaitu Mahasiswa tingkat III dan IV Prodi Matematika tidak memiliki perbedaan kompetensi yang signifikan.

Kompetensi Profesional II calon guru Prodi Matematika Tingkat III sebanyak 22\% memiliki kriteria sangat baik, 49\% memliki kriteria baik, dan 29\% memiliki kriteria kurang baik.
Sedangkan pada Prodi Pendidikan Matematika Tingkat IV sebanyak 20\% memiliki kriteria sangat baik, 74\% memiliki kriteria baik, dan 7\% memliki kriteria kurang baik. Dilihat dari hasil pengamatan ini, terlihat kemampuan calon guru dalam mengembangkan keprofesionalan melalui tindakan reflektif yaitu Mahasiswa tingkat III dan IV Prodi Matematika memliki perbedaan kompetensi yang signifikan. Mahasiswa Prodi Matematika tingkat IV lebih baik dibandingkan dengan tingkat III.

Kompetensi Personal calon guru Prodi Matematika Tingkat III sebanyak 50\% memiliki kriteria sangat baik dan 50\% memiliki kriteria baik. Sedangkan pada Prodi Pendidikan Matematika Tingkat IV sebanyak 51\% memiliki kriteria sangat baik, dan 49\% memiliki kriteria baik. Dilihat dari hasil pengamatan ini, terlihat kemampuan calon guru dalam bertindak sesuai norma, memiliki etos kerja, tanggung jawab yang tinggi, rasa bangga menjadi guru dan memiliki pribadi yang dewasa serta teladan mahasiswa tingkat III dan IV Prodi Matematika memiliki kompetensi yang sama.

Kompetensi sosial calon guru Prodi Matematika Tingkat III sebanyak 34\% memiliki kriteria sangat baik, 59\% memliki kriteria baik, dan 7\% memiliki kriteria kurang baik. Sedangkan pada Prodi Pendidikan Matematika Tingkat IV sebanyak $27 \%$ memiliki kriteria sangat baik, $67 \%$ memiliki kriteria baik, dan 6\% memliki kriteria kurang baik. Dilihat dari hasil pengamatan ini, terlihat kemampuan calon guru dalam bersikap inklusif, bertindak obyektif, dan tidak diskriminatif mahasiswa calon guru tingkat III dan IV Prodi Matematika tidak memiliki perbedaan kompetensi yang signifikan. Selain itu, para praktikan pun mampu membangun komunikasi dengan sesama guru, tenaga kependidikan, orang tua, peserta didik, dan masyarakat dengan baik.

Kompetensi Pedagogik calon guru Prodi Matematika Tingkat III sebanyak 29\% memiliki kriteria sangat baik, 64\% memliki kriteria baik, dan 7\% memiliki kriteria kurang baik. Sedangkan pada Prodi Pendidikan Matematika 
Tingkat IV sebanyak $34 \%$ memiliki kriteria sangat baik, 59\% memiliki kriteria baik, dan 7\% memliki kriteria kurang baik. Dilihat dari hasil pengamatan ini, terlihat kemampuan calon guru dalam menguasai karakter peserta didik, teori belajar, prinsip-prinsip pembelajaran, mengembangkan kurikulum, melakukan kegiatan yang mendidik, mengembangkan potensi peserta didik, membangun komunikasi dengan peserta didik, melakukan penilaan serta evaluasi mahasiswa calon guru tingkat III dan IV Prodi Matematika tidak memiliki perbedaan kompetensi yang signifikan. Praktikan memiliki kompetensi pedagogik dengan baik.

Kompetensi Sosial calon guru Prodi Matematika Tingkat III sebanyak 34\% memiliki kriteria sangat baik, 59\% memliki kriteria baik, dan $7 \%$ memiliki kriteria kurang baik. Sedangkan pada Prodi Pendidikan Matematika Tingkat IV sebanyak $27 \%$ memiliki kriteria sangat baik, 67\% memiliki kriteria baik, dan 6\% memliki kriteria kurang baik. Dilihat dari hasil pengamatan ini, terlihat kemampuan calon guru dalam bersikap inklusif, bertindak obyektif dan tidak diskriminatif mahasiswa calon guru tingkat III dan IV Prodi Matematika tidak memiliki perbedaan kompetensi yang signifikan. Selain itu, para praktikan pun mampu membangun komunikasi dengan sesama guru, tenaga kependidikan, orang tua, peserta didik, dan masyarakat dengan baik.

Kompetensi Pedagogik calon guru Prodi Matematika Tingkat III sebanyak 29\% memiliki kriteria sangat baik, 64\% memliki kriteria baik, dan 7\% memiliki kriteria kurang baik. Sedangkan pada Prodi Pendidikan Matematika Tingkat IV sebanyak $34 \%$ memiliki kriteria sangat baik, 59\% memiliki kriteria baik, dan 7\% memliki kriteria kurang baik. Dilihat dari hasil pengamatan ini, terlihat kemampuan calon guru dalam menguasai karakter peserta didik, teori belajar, prinsip-prinsip pembelajaran, mengembangkan kurikulum, melakukan kegiatan yang mendidik, mengembangkan potensi peserta didik, membangun komunikasi dengan peserta didik, melakukan penilaan serta evaluasi mahasiswa calon guru tingkat III dan
IV Prodi Matematika tidak memiliki perbedaan kompetensi yang signifikan. Praktikan memiliki kompetensi pedagogik dengan baik.

Data Penilaian Kinerja Calon guru matematika untuk empat kompetensi yang di nilai dilakukan dengan teknik observasi praktik mengajar bekerjasama dengan guru pamong dan wakil kepala sekolah yang di tugaskan. Hal ini terlihat seperti gambar 8 dan 9 dibawah ini.

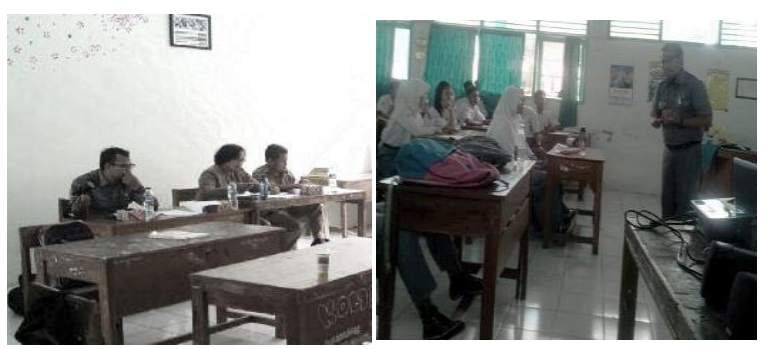

Gambar 8. Dokumentasi Kegaiatan Penelitian Observasi Praktik Mengajar

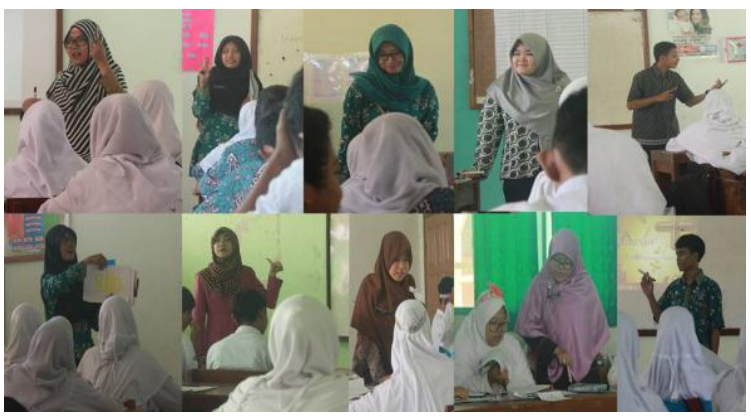

Gambar 9. Guru Praktikan PPL FKIP Unswagati Cirebon Disalah Satu SMA Kota Cirebon

\section{KESIMPULAN}

Berdasarkan data dan analsis hasil penelitian yang dilakukan tentang komptensi praktikan calon guru FKIP Unswagati Cirebon disalah satu SMA Kota Cirebon dapat disimpulkan bahwa kompetensi dasar yang harus dimiliki oleh mahasiswa calon guru meliputi kompetensi profesional, kompetensi personal, kompetensi sosial, dan kompetensi pedagogik. Penelitian ini membahas empat kompetensi tersebut berdasarkan tingkat mahasiswa yaitu 
Dede Trie Kurniawan, Setiyani,

Sri Maryanti

mahasiswa tingkat III dan IV pada Prodi Matematika, Prodi Pendidikan Ilmu Ekonomi, Prodi Bahasa Indonesia, dan Prodi Bahasa Inggris. Secara Garis Besar Praktikan Tingkat III lebih baik daripada praktikan tingkat IV dalam perolehan tingkat kompetensi calon guru.

Untuk penelitian lebih lanjut peneliti menyarankan agar memperluas sampel penelitian dengan kriteria perwakilan semua tingkat sekolah agar dapat mengambil kesimpulan yang lebih luas.

\section{DAFTAR PUSTAKA}

Arikunto, S \& Jabar, C.S.A. (2010). Evaluasi Program Pendidikan. Jakarta: Bumi Aksara.

Firman, harry. (.........). Proposal Pelaksanaan Evaluasi Semester Program PPGA Sampoerna Foundation.

Five Levels of Professioneal Development Evaluation. Tersedia Online: http://www.updc.org/.../13GuskeysFive-Levels-Matrix

Gill Nicholis, "Professional Development in Higher Education (new dimensions a directions)", London: Kogan, 2001

Guskey, Thomas R. (2000). Evaluating Professional Development. Tersedia Online:

http://books.google.co.id/books/about/ Evaluating Professional Development. html?id=CklqX4zgDtgC\&redir esc $=y$

Juanengsih, Nengsih. 2014. Rancangan Evaluasi Program Mata Kuliah Praktik Profesi Keguruan Terpadu (Ppkt) Pada Prodi Pendidikan Biologi Fakultas Ilmu Tarbiyah Dan Keguruan Uin Syarif Hidayatullah Jakarta. Makalah : UPI Bandung.

Mansyur, Jusman. (2008). Evaluasi Pelaksanaan Pendidikan dan Latihan Profesi Guru (PLPG) Program Sertifikasi Guru Pada LPTK Rayon 25 FKIP Universitas Tadulako
Menteri Pendidikan Nasional. (2005). Undangundang No. 14 Tahun 2005 tentang Guru dan Dosen. Jakarta.

Menteri Pendidikan Nasional. (2007). Peraturan Mendiknas Nomor 16 Tahun 2007 tentang Standar Kualifikasi Akademik dan Kompetensi Guru. Jakarta.

Mulyasa, E, "Standar Kompetensi dan Sertifikat Guru”, Bandung: ROSDA, 2013

Murni. (2012). Upaya Peningkatan Profesionalisme Guru Indonesia. [Online]. Tersedia: http://www.kompasberita.com/2012/o 7/upaya-peningkatan-profesionalismeguru-indonesia. [2 Novenber 2012]

Nurani, Suci. 2014. Standar Kompetensi Guru IPA. Makalah, UPI Bandung.

Peraturan Pemerintah RI No. 19 Tahun 2005 tentang Standar Nasional Pendidikan.

Rozak, Abdul, dkk. 2013. Pedoman Pelaksann PPL Kependidikan. Cirebon : FKIP Unswagati Cirebon

Royce, D., Thyer, B.A., Padgett, D.K. \& Logan, T.K. (2006). Program Evaluation: $A n$ Introduction. Belmont, CA: Thomson Brooks/Cole.

Sudrajat, A. (2008). Kompetensi Guru dan Peran Sekolah. Makalah: tidak diterbitkan.

Sulistiani. (2012). Rancangan Evaluasi Program Mata Kuliah Program Pengembangan Lapangan (PPL) Pada Program Studi Fisika Jurusan Pendidikan MIPA FKIP Universitas PGRI Palembang.

Undang-Undang No. 20 Tahun 2003 tentang Sistem Pendidikan Nasional. 